in animal studies has been shown to result in neuronal damage in wake promoting structures or disturbance in sleep architecture. $^{22} 23$ Notwithstanding, one can also look at the issue of sleep hypoxaemia and daytime sleepiness from other angles. Why was desaturation more severe in the sleepy group despite similar $\mathrm{AHI}$ ? Can the daytime sleepiness in those OSA individuals be a reflection of an overall propensity to sleep ${ }^{911}$ with diminished ventilatory response during nocturnal sleep, hence greater oxygen desaturation? Apart from hypoxaemia, is there any role for hypercarbia, the parameter in oblivion which is expected to be fluctuating alongside oxygen saturation?

Barceló's article $e^{3}$ has raised many more questions than it can answer. While researchers speculate on, and attempt to delineate, the complex relationships between OSA and its potential metabolic and neurobehavioural sequelae, it is important to confirm the findings of this work with further clinical trials. Furthermore, these two groups of subjects with similar severe OSA by AHI criteria and similar BMI, yet widely divergent degrees of daytime sleepiness, were probably highly selected for the purpose of addressing the authors' stated hypothesis. In our daily encounter, subjects would have a wide spectrum of severity of OSA, obesity and sleepiness. Given the numerous permutations in phenotypes and their underlying pathophysiological interactions, what demarcates clearly in the study sample may have very different consequences in the wider population of OSA subjects. This is perhaps the challenge of researchto search, and research.

Competing interests: None declared.

Thorax 2008;63:939-940. doi:10.1136/thx.2008.099689

\section{REFERENCES}

1. Tasali E, Ip MSM. Obstructive sleep apnea and metabolic syndrome: alterations in glucose metabolism and inflammation. Proc Am Thorac Soc 2008;5:207-17.

2. Seicean S, Kirchner HL, Gottlieb DJ, et al. Sleep disordered brathing and impaired glucose metabolism in normal-weight and overweight/obese individuals. Diabetes Care 2008:31:1001-6.

3. Barceló A, Barbé $F$, de la Peña $M$, et al. Insulin resistance and daytime sleepiness in patients with sleep apnea. Thorax 2008;63:946-50.

4. Barbé F, Mayoralas LR, Duran J, et al. Treatment with continuous positive airway pressure is not effective in patients with sleep apnea but no daytime sleepiness, a randomized, controlled trial. Ann Inter Med 2001;134:1015-23.

5. Robinson GV, Langford BA, Smith DM, et al. Predictors of blood pressure fall with continuous positive airway pressure (CPAP) treatment of obstructive sleep apnoea (OSA). Thorax 2008 Apr 3 (Epub ahead of print).

6. Guilleminault C, Partinen M, Quera-Salva MA, et al Determinants of daytime sleepiness in obstructive sleep apnea. Chest 1988;94:32-7.

7. Punjabi NM, O'Hearn DJ, Neubauer DN, et al. Modeling hypersomnia in sleep disordered breathing Am J Respir Crit Care Med 1999;159:1703-9.

8. Bixler EO, Vgontzas AN, Lin HM, et al. Excessive daytime sleepiness in a general population sample: the role of sleep apnea, age, obesity, diabetes and depression. J Clin Endocrinol Metab 2005:90:4510-15.

9. Roure N, Gomez S, Mediano 0, et al. Daytime sleepiness and polysomnography in obstructive sleep apnea patients. Sleep Med 2008 May 13 (Epub ahead of print).

10. Gozal D, Kheirandish L. Oxidant stress and inflammation in the snoring child: confluent pathways to upper airway pathogenesis and end-organ morbidity. Sleep Med Rev 2006;10:83-96.
11. Gottlieb DJ, O'Connor GT, Wil JB. Genome-wide association of sleep and circadian phenotypes. BMC Med Genet 2007;8(Suppl 1):59.

12. Ip M, Mokhlesi B. Sleep and glucose intolerance/ diabetes mellitus. Sleep Med Clin 2007;2:19.

13. Lindberg $\mathbf{E}$, Berne $\mathrm{C}$, Franklin KA, et al. Snoring and daytime sleepiness as risk factors for hypertension and diabetes in women-a population-based study. Respir Med 2007;101:1283-90.

14. Saaresranta T, Irjala K, Aittokallio T, et al. Sleep quality, daytime sleepiness and fasting insulin levels in women with chronic obstructive pulmonary disease. Respir Med 2005;99:856-63.

15. Vgontzas AN, Bixler EO, Chrousos GP. Obesityrelated sleepiness and fatigue: The role of the stress system and cytokines. Ann NY Acad Sci 2006;1083:329-44.

16. Knutson KL, Spiegel K, Penev P, et al. The metabolic consequences of sleep deprivation. Sleep Med Rev 2007; 11:163-78

17. de la Pena BM, Serpero LD, Barcelo A, et al. Inflammatory proteins in patients with obstructive sleep apnea with and without daytime sleepiness. Sleep Breath 2007:11:177-85.

18. Ip MSM, Lam B, Ng MMT, et al. Insulin resistance is independently associated with obstructive sleep apnea. Am J Respir Crit Care Med 2002;165:670-6.

19. Punjabi NM, Shahar E, Redline S, et al, for the Sleep Heart Health Study Investigators. Sleep disordered breathing, glucose intolerance and insulin reistance. Am J Epidemiol 2004;160:521-30.

20. Polotsky VY, Li J, Punjabi NM, et al. Intermittent hypoxia increases insulin resistance in genetically obese mice. J Physiol 2003;552:253-64.

21. Liyori $\mathbf{N}$, Alonso LC, Li J, et al. Intermittent hypoxia causes insulin resistance in lean mice independent of autonomic activity. Am J Respir Crit Care Med 2007:175:851-7.

22. Veasey SC, Davis CW, Fenik P, et al. Long-term intermittent hypoxia in mice: protracted hypersomnolence with oxidative injury to sleep-wake brain regions. Sleep 2004:27:194-201.

23. Polotsky VY, Rubin AE, Balbir A, et al. Intermittent hypoxia causes REM sleep deficits and decreases EEG delta power in NREM sleep in the C57BL/6J mouse. Sleep Med 2006;7:7-16.

\title{
Antibiotics at COPD exacerbations: the debate continues
}

\section{Jadwiga A Wedzicha}

The course of chronic obstructive pulmonary disease (COPD) is affected by the presence of exacerbations that are episodes of worsening of respiratory symptoms commonly triggered by airway

Correspondence to: Professor Jadwiga A Wedzicha, Academic Unit of Respiratory Medicine, Royal Free and University College Medical School, Rowland Hill Street, Hampstead, London NW3 2PF, UK; J.A.Wedzicha@ medsch.ucl.ac.uk infections, including respiratory viruses and airway bacteria. ${ }^{1}$ COPD exacerbations have important adverse effects on health status ${ }^{2}$ and mortality ${ }^{3}$ and affect the course of the disease. ${ }^{4}$ Thus there is considerable interest in the effectiveness of interventions used both to treat exacerbations and prevent further events.

Exacerbations are usually treated with oral corticosteroids and/or antibiotics depending on exacerbation severity and the nature of the symptoms. There is now considerable evidence for benefit of a course of oral corticosteroids at exacerba$\operatorname{tion}^{56}$ and also for antibiotics when two of the three symptoms of increased dyspnoea, sputum volume and purulence are present. ${ }^{7}$ However, there is still some controversy concerning the role of antibiotics at COPD exacerbation, especially in studies performed in primary care ${ }^{8}$ where generally patients with milder disease have been recruited. There is now clear documentation of the involvement of bacteria at exacerbations with increased bacterial detection and load, ${ }^{9}$ while bacterial strain changes have also been associated with development of exacerbations. ${ }^{10}$ Eradication of bacteria in the airways with antibiotics prescribed at exacerbation has been linked to exacerbation recovery and reduction in airway inflammatory markers. ${ }^{11}$ Some of the controversy regarding 
antibiotics relates to the fact that patients with COPD show lower airway bacterial colonisation (LABC) in the stable state, and increased $L A B C$ is associated with greater airway inflammation ${ }^{12}$ and exacerbation frequency. ${ }^{13}$

There are a number of reasons for the observed variation in outcomes seen with antibiotic trials at COPD exacerbations. A number of different outcomes have been utilised in clinical trials, including exacerbation lengths and recovery, symptom recovery, time to the next exacerbation, treatment failure and mortality. Often patients with COPD recruited into trials have been markedly heterogeneous with respect to lung function, stable treatment, comorbidity and exacerbation frequency. Outcomes from antibiotic studies have been measured mainly in the short term, and there is relatively little information on longer term outcomes. In a further analysis from the MOSAIC trial of the antibiotic moxifloxacin versus standard therapy at exacerbations, Wilson et al showed that the response to moxifloxacin was worse in the short term (up to 10 days) in patients with coexistent cardiac disease. ${ }^{14}$ In contrast, when exploring longer term outcomes up to 9 months after the study onset, response to moxifloxacin was greater in older patients who were aged over 65 years and in those with higher exacerbation frequencies. Thus the benefit of antibiotics are more pronounced in frequent exacerbators and this is consistent with the fact that these patients show a higher airway bacterial load in the stable state. ${ }^{13}$

Further information on longer term outcomes with antibiotic therapies at COPD exacerbations is now available. Roede and colleagues ${ }^{15}$ report on the longer term outcomes of antibiotic therapy in a population based cohort from the Dutch PHARMO database (see page 968). This database includes pharmacy dispensing records from community pharmacies and secondary care on 2 million residents in The Netherlands. Patients with airway obstruction who had medication dispensed for airway disease were included if aged over 50 years to exclude patients with asthma as far as possible. Exacerbations were detected from courses of oral corticosteroids prescribed, as it can be assumed that these are prescribed usually for exacerbation events. Events where antibiotics were prescribed without oral corticosteroids were excluded as there was no information on the diagnostic nature of this episode. A minimum interval between individual steroid courses was taken as 3 weeks to avoid confusion over relapsed and new exacerbations. The novel aspect of this study was that the authors not only followed the patients from the initial exacerbation to the next or second event, but also from the second to the third exacerbations. The main comparisons were between exacerbations treated with oral corticosteroids alone and those treated with steroids combined with a course of antibiotics. Results showed that the time to the next/second exacerbation was longer when cortiocosteroids were combined with antibiotics rather than corticosteroids alone, and a similar result, although more pronounced effect, was found between the second and third exacerbation. There was also a reduction in all cause mortality in the oral corticosteroid and antibiotic group followed after the first exacerbation, although the authors are rightly cautious in suggesting a survival benefit as the cause of death was not known in the majority of the cases.

This study suffers from the usual disadvantages of being a large database study without information on spirometry to adequately classify the patients. The two exacerbation treated groups were also well matched for age, gender and comorbidity, although patients given both antibiotics and corticosteroids at exacerbation had a greater number of stable medications dispensed with fewer hospital admissions. Thus if these were a more severe patient group based on prescribed therapies, one would expect them to have shorter times to next exacerbations and this would tend to decrease the size of the treatment effect. On the other hand, long term bronchodilators and inhaled corticosteroids can all reduce exacerbation frequency in patients with $\mathrm{COPD}^{16}{ }^{17}$ thus increasing the time to the next exacerbation. Exacerbations where antibiotics were used on their own were excluded, with the result that the overall study cohort exacerbation frequency was reduced.

These results describe the longer term consequences of using antibiotics in COPD exacerbations. Although we assume that antibiotics at exacerbations reduce the airway bacterial load and thus the inflammatory load at the particular exacerbation, a single course of antibiotics may also have a significant effect on the degree of LABC in the subsequent stable phase. If $\mathrm{LABC}$ is reduced by the first antibiotic course, then this reduction in load may enhance the benefit of antibiotics on subsequent exacerbations, although any potential mechanism leading to this observation needs further study. In this study, the class of antibiotics used did not have any effect on the outcomes, but therapy specific for the colonising or infecting bacteria may show greater benefit. On the other hand, there may be other explanations for the effects observed. As many exacerbations are triggered by respiratory viral infections, ${ }^{18}$ it is possible that use of oral steroids alone can increase the chance of secondary bacterial infection at an exacerbation and antibiotic therapy prevents this occurring with improved outcome. Patients prescribed antibiotics at exacerbation usually have increased sputum purulence and volume and it is also possible that symptoms related to sputum prompt patients to seek treatment for their exacerbation early after onset or commence self-management resulting in better outcomes. ${ }^{19}$ The study by Roede and colleagues $^{15}$ shows that patients treated with steroids and antibiotics had more stable medications dispensed, including inhaled corticosteroids. In a recent study, patients prescribed an inhaled corticosteroid in addition to a long acting $\beta$ agonist had a greater requirement for antibiotics at exacerbation than patients taking a long acting anticholinergic bronchodilator alone. ${ }^{20}$ This suggests that an individual patient's stable medication may have differential effects on the character of their exacerbation and this in turn affects the nature of the therapy prescribed.

It is now clear that COPD exacerbations are complex events, occurring in patients with wide variation of disease severity, exacerbation susceptibility, underlying $\mathrm{LABC}$ and airway inflammation. They are associated with a number of interacting causative factors ${ }^{21-23}$ and the character of an exacerbation may be modulated by the nature of the patient's stable medication. ${ }^{18}$ Thus future clinical trials of exacerbation therapy must be performed in carefully phenotyped patients with COPD with assessment of both stable and exacerbation airway microbiology, using validated outcomes and longer term follow-up. Meanwhile, I believe we have now generated more questions to be answered about the use of antibiotics and oral corticosteroids either alone or in combination to treat COPD exacerbations. The antibiotic debate will continue for some time to come.

Competing interests: None declared.

Thorax 2008;63:940-942. doi:10.1136/thx.2008.103416 


\section{REFERENCES}

1. Wedzicha JA, Seemungal TAR. COPD exacerbations: defining their cause and prevention. Lancet 2007;370:786-96.

2. Seemungal TAR, Donaldson GC, Paul EA, et al. Effect of exacerbation on quality of life in patients with chronic obstructive pulmonary disease. Am J Respir Crit Care Med 1998;151:1418-22.

3. Soler-Cataluna JJ, Martinez-Garcia MA, Roman Sanchez P, et al. Severe acute exacerbations and mortality in patients with chronic obstructive pulmonary disease. Thorax 2005;60:925-31.

4. Donaldson GC, Seemungal TAR, Bhowmik A, et al. The relationship between exacerbation frequency and lung function decline in chronic obstructive pulmonary disease. Thorax 2002:57:847-52.

5. Davies L, Angus RM, Calverley PMA. Oral corticosteroids in patients admitted to hospital with exacerbations of chronnic obstructive pulmonary disease: a prospective randomised controlled trial. Lancet 1999;354:456-60.

6. Niewoehner DE, Erbland ML, Deupree RH, et al. Effect of systemic glucocorticoids on exacerbations of chronic obstuctive pulmonary disease. N Engl J Med 1999:340:1941-7.

7. Anthonisen NR, Manfreda J, Warren CP, et al. Antibiotic therapy in exacerbations of chronic obstructive pulmonary disease. Ann Intern Med 1987:106:196-204.

8. Sachs AP, Koeter GH, Groenier KH, et al. Changes in symptoms, peak expiratory flow, and sputum flora during treatment with antibiotics of exacerbations in patients with chronic obstructive pulmonary disease in general practice. Thorax 1995:50:758-63.
9. Monso E, Ruiz J, Rosell A, et al. Bacterial infection in chronic obstructive airways disease: a study of stable and exacerbated patients using the protected specimen brush. Am J Respir Crit Care Med 1995;152:1316-20.

10. Sethi S, Evans N, Grant BJ, et al. New strains of bacteria and exacerbations of chronic obstructive pulmonary disease. N Engl J Med 2002;347:465-71.

11. White AJ, Gompertz S, Bayley DL, et al. Resolution of bronchial inflammation is related to bacterial eradication following treatment of exacerbations of chronic bronchitis. Thorax 2003:58:680-5.

12. Hill AT, Campbell EJ, Hill SL, et al. Association between airway bacterial load and markers of airway inflammation in patients with stable chronic bronchitis. Am J Med 2000;109:288-95.

13. Patel IS, Seemungal TAR, Wilks M, et al. Relationship between bacterial colonisation and the frequency, character and severity of COPD exacerbations. Thorax 2002:57:759-64.

14. Wilson R, Jones P, Schaberg $T$, et al, for the MOSAIC Study Group. Antibiotic treatment and factors influencing short and long term outcomes of acute exacerbations of chronic bronchitis. Thorax 2006:61:337-42

15. Roede BM, Bresser P, Bindels PJE, et al. Antibiotic treatment is associated with reduced risk of a subsequent exacerbation in obstructive lung disease: an historical population based cohort. Thorax 2008;63:968-73.

16. Niewoehner DE, Rice K, Cote C, et al. Prevention of exacerbations of chronic obstructive pulmonary disease with tiotropium, a once daily inhaled anticholinergic bronchodilator: a randomised trial. Ann Intern Med 2005;143:317-26.

17. Calverley PM, Anderson JA, Celli B, et al. Salmeterol and fluticasone propionate and survival in chronic obstructive pulmonary disease. N Engl J Med 2007; 356:775-89.

18. Seemungal TAR, Harper-Owen R, Bhowmik A, et al. Respiratory viruses, symptoms and inflammatory markers in acute exacerbations and stable chronic obstructive pulmonary disease. Am J Respir Crit Care Med 2001;164:1618-23

19. Wilkinson TMA, Donaldson GC, Hurst JR, et al. Impact of reporting and early therapy on outcome of exacerbations of COPD. Am J Respir Crit Care Med 2004:169:1298-303.

20. Wedzicha JA, Calverley PMA, Seemungal TA, et al, for the INSPIRE Investigators. The prevention of chronic obstructive pulmonary disease exacerbations by salmeterol/fluticasone propionate or tiotropium bromide. Am J Respir Crit Care Med 2008;177:19-26.

21. Sapey E, Stockley RA. COPD exacerbations 2: Aetiology. Thorax 2006;61:250-8.

22. Wilkinson TMA, Hurst JR, Perera WR, et al Interactions between lower airway bacterial and rhinoviral infection at exacerbations of chronic obstructive pulmonary disease. Chest 2006:129:317-24.

23. Papi A, Bellettato CM, Braccioni F, et al Infections and airway inflammation in chronic obstructive pulmonary disease severe exacerbations. Am J Respir Crit Care Med 2006:173:1114-21.

\section{Wheezing phenotypes}

\section{Louis I Landau}

There are increasing reports of excellent data on wheezing phenotypes in early childhood. ${ }^{1}$ Despite some contradictory findings, generally based on differences in definitions used or ages studied, the findings are gradually providing valuable perspectives towards understanding this very common symptom. It is clear that much of respiratory disease throughout life is programmed during fetal life and the early years after birth. The patterns differ between developing and developed countries, apparently related to differences in microbial exposure, diet and exposure to cigarette smoke. ${ }^{23}$ The outcomes are probably mediated through the effects of these agents, timing of these exposures being critical, on airway development and maturation of the immune system. ${ }^{4}$ The airways may be structurally smaller due to abnormalities of the wall size, function of the smooth muscle or increased thickness of the mucosa. Abnormal maturation of the immune

Correspondence to: Dr L I Landau, The University of Western Australia, Crawley, WA 6009, Australia;

llandau@meddent.uwa.edu.au system influences the response to both allergens and microbes promoting either hypersensitivity or tolerance. ${ }^{5}$

Cough and wheeze are very common symptoms in the early years of life with more than $60 \%$ coughing and more than $30 \%$ wheezing in the first year. ${ }^{6}$ Wheeze is a cardinal symptom of asthma but, in the first year of life, more than half is likely to be due to causes other than asthma such as congenitally small airways, bronchiolitis, cystic fibrosis, congenital heart disease, aspiration syndromes, social disadvantage and chronic neonatal lung disease.

A predisposition to wheeze is seen with small airways related to factors such as male gender and exposure to maternal smoking. ${ }^{7}$ It is more likely at this age due to a lack of collateral ventilation, a weak chest wall with reduced tethering of the airways, increased smooth muscle in the peripheral airways (particularly in preterm infants) and an immature immune system.

There have been many genes associated with asthma prevalence, severity or response to drugs, although no single gene accounts for more than $10 \%$ of the asthma phenotype. ${ }^{8}$ Those identified generally relate to $\beta_{2}$ receptor activity, immune maturation or function and leucotriene metabolism.

Prospective longitudinal studies commencing before birth such as those from Tucson, ${ }^{9}$ Melbourne, ${ }^{10}$ Perth ${ }^{11}$ and Bristol ${ }^{12}$ have been reported; a follow-up from this last study by Henderson and colleagues is included in this issue of Thorax (see page 974). They have defined four or more patterns of preschool wheezing: early transient (first year only), late transient (second or third year), persistent (from first year to beyond 6 years) and late onset (commencing after 3 years). Better information on these phenotypes has been obtained with measurements of lung function in this age group by forced expiratory flows using the rapid thoracic compression technique, ${ }^{13}$ tidal breath analysis ${ }^{14}$ interrupter resistance measurements, ${ }^{15}$ multiple breath gas washout and lung volumes, ${ }^{16}$ exhaled nitric oxide, ${ }^{17}$ analysis of induced sputum ${ }^{18}$ and airway hyper-responsiveness. ${ }^{19}$

Those with early transient wheezing have been found to have low flow rates and airway hyper-responsiveness before the onset of symptoms associated with male gender and maternal smoking. Other triggers are being sought. One manifestation of this pattern is bronchiolitis in the 